\title{
Is some white matter damage in preterm neonates induced by a human pestivirus?
}

We offer the hypothesis that some forms of cerebral white matter damage (WMD) in preterm neonates might be caused by transplacental viral infection of the fetus during the first or second trimester of pregnancy. Potts and colleagues ${ }^{1}$ speculated on the possible role of a human pestivirus (PV) in the aetiology of congenital microcephaly. We suggest PV might be a candidate virus for some form of WMD. We further offer our view that a virus induced cytokine cascade might place the fetus at double jeopardy - that is, disturb white matter development and lead to preterm birth.

\section{Virus related WMD}

White matter damage is the most important predictor of childhood neuromotor disability among those born preterm. About $50 \%$ of infants who have echolucent zones in the periventricular white matter or ventriculomegaly on neonatal cranial ultrasound scans subsequently develop cerebral palsy. ${ }^{2}$ The multiple expressions of WMD, both on histological examination and neonatal cranial ultrasound scan, as focal, multifocal, or diffuse WMD, ${ }^{3}$ make multiple aetiologies likely. Some forms of WMD might be related to a hypoxic-ischaemic insult, but others might be associated with infection.

Four types of WMD can be distinguished on the basis of their location, histological patterns, and ultrasonographic appearance. ${ }^{3}$ The first two forms comprise unifocal haemorrhagic infarctions, leading to periventricular echodensities on neonatal cranial ultrasound images, and multifocal necroses, leading to hypoechoic ultrasound images often described as "periventricular leucomalacia" (PVL). Current textbooks focus on fetal or newborn hypoxiaischaemia as the pathogenesis of focal and multifocal forms of WMD. ${ }^{4}$ This is supported by studies showing that periventricular white matter damage can be induced by ligating the carotid arteries of mongrel pups. ${ }^{5}$ However, comparable white matter lesions have been induced in various animal models using bacterial and viral challenges. Newborn kittens exposed to intraperitoneal bacterial endotoxin ${ }^{6}$ and the offspring of rabbits who were exposed to inoculation of Escherichia coli via hysteroscopy developed WMD. ${ }^{7}$ Maternal infection with pestiviruses led to dysmyelination in lambs ${ }^{89}$ and cystic changes in the developing periventricular white matter of lamb fetuses. ${ }^{10}$

The two remaining diffuse WMD subtypes are histologically defined by either astrocytosis or pyknotic nuclei. These diffuse forms of WMD are not readily identified on early neonatal cranial ultrasound images. Their tendency to impair myelination probably results in ventriculomegaly on late neonatal ultrasound scans. Such a diffuse process raises the possibility that either or both is induced by a generalised infection of the developing brain.

White matter involvement is common in viral infections of the central nervous system. White matter damage, disturbances of myelination, and subsequent microcephaly follow herpes simplex encephalitis, ${ }^{11}$ exposure to rubella virus in utero, ${ }^{12} 1314$ and canine distemper virus infection. ${ }^{15}$
Microcephaly, dysmyelination, glial proliferation, ${ }^{16}$ ventricular enlargement, and extensive necroses in the white matter $^{10}$ are associated with pestivirus infection. Because these types of damage so closely resemble those of WMD in preterm neonates, we suggest that human pestivirus is a likely mediator of virus induced WMD.

If an unidentified virus infection during pregnancy indeed leads to transplacental infection of the fetus and subsequent WMD, the subclinical nature of some virus infections during pregnancy ${ }^{17}$ might explain why a viral cause of WMD has not yet been identified.

\section{Pestivirus infections}

The two major PVs in animals are border disease virus (BDV) and bovine virus diarrhoea virus (BVDV). Pestivirus infections were thought to occur exclusively in animals until Giangaspero and coworkers recently reported the presence of specific anti-BVDV antibodies in up to $87 \%$ of animal handlers and veterinarians. ${ }^{18}$ Since then, lower prevalences of $15-16 \%$ have been reported in adults. ${ }^{19}{ }^{20}$ Among children under 2 years, pestivirus antigens were present in $24 \%$ of specimens from diarrhoea episodes that could not be explained by more common enteric pathogens. ${ }^{21}$ Thus pestivirus infections occur in humans, although infection during pregnancy and a possible association with preterm birth or WMD have not yet been investigated.

Exposure to the pestivirus BDV of lambs leads to hypomyelination of their brains. ${ }^{9}$ Hypomyelination is a symptom of some diffuse forms of WMD. ${ }^{3}$ Infection with the pestivirus BVDV leads to necroses and cysts in the periventricular white matter and enlarged ventricles in lamb fetuses. ${ }^{10}$ All of these are expressions of WMD in preterm human babies. ${ }^{34}$

Infection with BDV is accompanied by a decrease in thyroid hormone activity in lambs. ${ }^{8}$ Low thyroid hormone values are also an important predictor of maldevelopment among preterm infants. ${ }^{22-24}$ After adjustment for gestational age, Reuss and colleagues ${ }^{23}$ found an 11-fold increased risk of disabling cerebral palsy among preterm infants with severe hypothyroxinaemia. What is still unclear is whether low thyroid hormone values are the cause of the brain damage or merely an indicator of illness severity and/or immaturity related vulnerability, which conveys risk information above and beyond that given by gestational age information.

\section{Does a virus induced cytokine cascade cause both preterm birth and WMD?}

A common antecedent of both preterm birth and WMD could serve as a likely explanation for why WMD is more common among preterm than term infants. ${ }^{25} \mathrm{~A}$ transplacental virus infection early in pregnancy potentially fulfills the criteria of such a common antecedent (fig 1).

One in four women with asymptomatic shedding of herpes simplex virus at the onset of labour gave birth before the completion of 37 weeks of gestation; this percentage was only $12 \%$ among unaffected controls. ${ }^{17}$ In two other studies not involving uninfected newborns for comparison, 


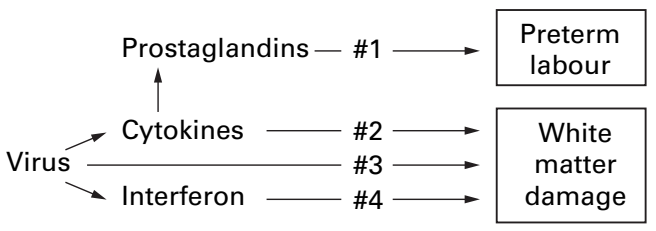

Figure 1 Hypothetical model showing how a transplacental viral infection early in pregnancy might lead to both preterm birth and white matter damage in neonates.

$41 \%{ }^{26}$ and $48 \%{ }^{27}$ of infants with neonatal herpes simplex infection were born before term. Herpesviridae stimulate the production of cytokines such as IL- $1 \beta$ and TNF $\alpha$ by peripheral blood mononuclear cells. ${ }^{28}{ }^{29}$ In maternal intrauterine infection these cytokines are presumably involved in a pro-inflammatory cascade eventually leading to prostaglandin induced preterm uterine contractions. ${ }^{30}$ Thus cytokines might offer the molecular link between virus infection and preterm birth (fig 1; pathway 1).

We recently reviewed the evidence that the proinflammatory cytokines IL-1, IL-6, and TNF $\alpha$ are produced at various levels of the materno-fetal unit (placenta, fetal blood cells, fetal microglia and astrocytes), can enter the fetal brain after crossing the placenta and blood-brain barrier, and might damage the white matter via various mechanisms including direct tissue damage and endothelial and/or ependymal disruption. ${ }^{31}$ Cytokines might be involved in the cytopathic effect of pestivirus infection in animals. ${ }^{32}$ In parallel, we argue here that cytokines are likely to be involved in the proposed virus related aetiology of WMD in preterm human babies (fig 1, pathway 2). For example, astrocytes produce $\alpha$ and $\beta$ interferons, as well as TNF and IL-6, after stimulation with a neurotrophic (Newcastle disease) paramyxovirus. ${ }^{33}$ These cytokines have also been associated with WMD in preterm babies. ${ }^{34-36}$

Recently, IFN $\alpha$ has been detected in $29 \%$ of cases of unexplained fetal ventriculomegaly but in only $1 \%$ of controls. ${ }^{37}$ Although IFN $\alpha$ might merely be a marker of virus induced WMD (fig 1, pathway 3), white matter abnormalities $^{38}$ and cerebral palsy ${ }^{39}$ are among the adverse effects of treatment with interferon. Therefore, a directly damaging effect of IFN $\alpha$ (fig 1, pathway 4) on the developing white matter is possible.

\section{Testing the hypothesis}

Our hypothesis that a transplacental human pestivirus infection might be involved in the aetiology of WMD in preterm neonates is difficult to test. We consider the epidemiological approach, and in particular a case-control study design to be most rewarding. If a human pestivirus-like infection is indeed related to WMD, then characteristics of such an infection should be found significantly more often among preterm newborns with WMD than among non-affected controls, while adjusting for potential confounders such as gestational age. Despite the necessity to conduct a large scale, multicentre study to obtain a sufficient number of WMD cases, we believe that the opportunity to identify a possibly preventable antecedent of WMD in the preterm neonate would be worth the effort.

This work was supported by National Institute for Neurologic Disorders and Stroke Grant NS 27306 and United Cerebral Palsy Research and Educational Foundation Grant R-712-96.

OLAF DAMMANN

ALAN LEVITON

Neuroepidemiology Unit, Department of Neurology,

Children's Hospital and Harvard Medical School, Boston, MA 02115, USA E-mail dammann_o@a1.tch.harvard.edu

1 Potts BJ, Sever JL, Tzan NR, Huddleston D, Elder GA. Possible role of pestiviruses in microcephaly. Lancet 1987;i:972.
2 Dammann O, Leviton A. The role of perinatal brain damage in developmental disabilities: an epidemiologic perspective. Mental Retard Dev Disabil Res Rev 1997;3:13-21.

3 Leviton A, Gilles F. Ventriculomegaly, delayed myelination, white matter hypoplasia, and "periventricular" leukomalacia: how are they related? Pediatr Neurol 1996;15:127-36.

4 Volpe JJ. Neurology of the newborn. Philadelphia: W B Saunders, 1995.

5 Yoshioka $\mathrm{H}$, Goma $\mathrm{H}$, Nioka S, et al. Bilateral carotid artery occlusion causes periventricular leukomalacia in neonatal dogs. Dev Brain Res 1994;78:273-8. Gilles FH, Leviton A, Kerr CS. Endotoxin leukencephalopathy in the telencephalon of the newborn kitten. F Neurol Sci 1976;27:183-91.

7 Yoon BH, Kim CJ, Romero R, et al. Experimentally induced intrauterine infection causes fetal brain white matter lesions in rabbits. Am $\mathcal{F}$ Obstet Gynecol 1997;177:797-802.

8 Anderson CA, Higgins RJ, Smith ME, Osburn Bl. Border disease. Virus induced decrease in thyroid hormone levels with associated hypomyelination. Lab Invest 1987;57:168-75.

9 Anderson CA, Sawyer M, Higgins RJ, East N, Osburn Bl. Experimentally induced ovine border disease: extensive hypomyelination with minimal induced ovine border disease: extensive hypomyelination with min
viral antigen in neonatal spinal cord. Am f Vet Res 1987;48:499-503.

10 Hewicker-Trautwein M, Trautwein G. Porencephaly, hydranencephaly and leukoencephalopathy in ovine fetuses following transplacental infection with bovine virus diarrhoea virus: distribution of viral antigen and characterization of cellular response. Acta Neuropathol 1994;87:385-97.

11 Tamura T, Morikawa A, Kikuchi K. Diffuse white matter lesions associated with herpes simplex encephalitis as observed on magnetic resonance imaging. Brain Dev 1996;18:150-2.

12 Macfarlane DW, Boyd RD, Dodrill CB, Tufts E. Intrauterine rubella, head size, and intellect. Pediatrics 1975;55:797-801.

13 Yamashita Y, Matsuishi T, Murakami Y, et al. Neuroimaging findings (ultrasonograpy, CT, MRI) in three infants with congenital rubella syndrome. Pediatr Radiol 1991;21:547-9.

14 Lane B, Sullivan EV, Lim KO, et al. White matter MR hyper intensities in adult patients with congenital rubella. Am f Neuroradiol 1996;17:99-103.

15 Graber HU, Müller CF, Vandevelde M, Zurbriggen A. Restricted infection with canine distemper virus leads to down-regulation of myelin gene transcription in cultured oligodendrocytes. Acta Neuropathol 1995;90:312-8.

16 Potts BJ, Berry LJ, Osburn Bl, Johnson KP. Viral persistence and abnormalities of the central nervous system after congenital infection of abnormalities of the central nervous system after congenital

17 Brown ZA, Benedetti J, Selke S, Ashley R, Watts DH, Corey L. Asymptomatic maternal shedding of herpes simplex virus at the onset of labour: relationship to preterm labour. Obstet Gynecol 1996;87:483-8.

18 Giangaspero M, Wellemans G, Vanopdenbosch E, Belloli A, Verhulst A. Bovine viral diarrhoea. Lancet 1988;ii: 110

19 Wilks CR, Abraham G, Blackmore DK. Bovine pestivirus and human infection. Lancet 1989;i:107.

20 Giangaspero M, Vacirca G, Morgan D, et al. Anti-bovine viral diarrhoea virus antibodies in adult Zambian patients infected with the human immunodeficiency virus. Int f STD AIDS 1993;4:300-2.

21 Yolken R, Dubovi E, Leister F, Reid R, Almeido-Hill J, Santosham M. Infantile gastroenteritis associated with excretion of pestivirus antigens. Lancet 1989;i:517-20.

22 Den Ouden AL, Kok JH, Verkerk PH, Brand R, Verloove-Vanhorick SP. The relation between neonatal thyroxine levels and neurodevelopmental outcome at age five and nine years in a national cohort of very preterm and/or very low birth weight infants. Pediatr Res 1996;39:142-5.

23 Reuss ML, Paneth N, Pinto-Martin JA, Lorenz JM, Susser M. The relation of transient hypothyroxinemia in preterm infants to neurologic development at two years of age. $N$ Engl f Med 1996;334:821-7.

24 Lucas A, Morley R, Fewtrell MS. Low triiodothyronine concentration in preterm infants and subsequent intelligence quotient (IQ) at 8 year follow up. BMF 1996;312:1132-3

25 Leviton A, Paneth N. White matter damage in preterm newborns - an epidemiologic perspective. Early Hum Dev 1990;24:1-22.

26 Stone KM, Brooks CA, Guinan ME, Alexander ER. National surveillance for neonatal herpes simplex virus infections. Sex Transm Dis 1989;16:152-6.

27 Whitley RJ, Nahmias AJ, Visintine AM, Fleming CL, Alford CA. The natural history of herpes simplex virus infection of mother and newborn. Pediatrics 1980;66:489-94

28 Flamand L, Gosselin J, D'Addario M, et al. Human herpes virus 6 induces interleukin- $1 \beta$ and tumour necrosis factor alpha, but not interleukin-6, in peripheral blood mononuclear cell cultures. F Virol 1991;65:5105-10.

29 Gosselin J, Flamand L, D'Addario M, et al. Modulatory effects of EbsteinBarr, herpes simplex, and human herpes- 6 viral infections and confections on cytokines synthesis. F Immunol 1992;149:181-7.

30 Gomez R, Romeo R, Edwin SS, David C. Pathogenesis of preterm labour and preterm premature rupture of membranes associated with intra amniand preterm premature rupture of membranes associate

31 Dammann O, Leviton A. Maternal intrauterine infection, cytokines, and brain damage in the preterm newborn. Pediatr Res 1997;42:1-8.

32 Bielefeldt Ohmann H, Babiuk LA. Influence of interferons $\alpha 1$ and $\gamma$ and of tumour necrosis factor on persistent infection with bovine viral diarrhoea virus in vitro. $\mathcal{F}$ Gen Virol 1988; 69:1399-403

33 Lieberman AP, Pitha PM, Shin HS, Shin ML. Production of tumour necrosis factor and other cytokines by astrocytes stimulated with lipopolysaccharide or a neurotropic virus. Proc Natl Acad Sci USA 1989;86:348-52.

34 Yoon BH, Romeo R, Yang SH, et al. Interleukin-6 concentrations in umbilical cord plasma are elevated in neonates with white matter lesions associated with periventricular leukomalacia. Am $\mathcal{7}$ Obstet Gynecol 1996;174:1433-40.

35 Yoon $\mathrm{BH}$, Jun JK, Romeo R, et al. Amniotic fluid inflammatory cytokines (interleukin- 6 , interleukin- $1 \beta$ and tumour necrosis factor- $\alpha$ ), neonatal white matter lesions, and cerebral palsy. Am F Obstet Gynecol 1997;177:19-26.

36 Deguchi K, Mizoguchi M, Takashima S. Immunohistochemical expression of tumour necrosis factor a in neonatal leukomalacia. Pediatr Neurol of tumour necros

37 Dommergues M, Mahieu-Caputo D, Fallet-Bianco C, et al. Fetal serum interferon-alpha suggests viral infection as the aetiology of unexplained lateral cerebral ventriculomegaly. Prenat Diagn 1996;16:883-92.

38 Mitsuyama Y, Hashiguchi H, Murayama T, Koono M, Nishi S. An autopsied case of interferon encephalopathy. Fpn f Psychiatry Neurol 1992;46:741 -8.

39 Vesikari T, Nuutila A, Cantell K. Neurologic sequelae following interferon therapy of juvenile laryngeal papilloma. Acta Paediatr Scand 1988;77:619-22. 